\title{
The Eastern heart and Galen's ventricle: a historical review of the purpose of the brain
}

\author{
Mirza N. Baig, M.D., Ph.D., ${ }^{1}$ Faheem Chishty, M.ED., ${ }^{2}$ Phillip Immesoete, M.D., ${ }^{1}$ \\ AND Chris S. KARAS, M.D. ${ }^{1}$
}

'Department of Neurological Surgery, Ohio State University, Columbus, Ohio; and ${ }^{2}$ University of Maryland, College Park, Maryland

\begin{abstract}
$\checkmark$ The seat of consciousness has not always been thought to reside in the brain. Its "source" is as varied as the cultures of those who have sought it. At present, although most may agree that the central nervous system is held to be the root of individualism in much of Western philosophy, this has not always been the case, and this viewpoint is certainly not unanimously accepted across all cultures today.

In this paper the authors undertook a literary review of ancient texts of both Eastern and Western societies as well as modern writings on the organic counterpart to the soul. The authors have studied both ancient Greek and Roman material as well as Islamic and Eastern philosophy.

Several specific aspects of the human body have often been proposed as the seat of consciousness, not only in medical texts, but also within historical documents, poetry, legal proceedings, and religious literature. Among the most prominently proposed have been the heart and breath, favoring a cardiopulmonary seat of individualism. This understanding was by no means stagnant, but evolved over time, as did the role of the brain in the definition of what it means to be human.

Even in the 21st century, no clear consensus exists between or within communities, scientific or otherwise, on the brain's capacity for making us who we are. Perhaps, by its nature, our consciousness-and our awareness of our surroundings and ourselves - is a function of what surrounds us, and must therefore change as the world changes and as we change. (DOI: 10.3171/FOC-07/07/E3)
\end{abstract}

KEY WORDS • consciousness • Galen • history of neurosurgery • Ibn Sina

$\mathrm{P}$ HILOSOPHERS, SCIENTISTS, AND SPIRITUALISTS have debated the seat of consciousness since the birth of civilization. Hypotheses in both modern and ancient literature consider the cardiopulmonary system, an external soul, or the brain as possibly responsible for thought control and consciousness. Unfortunately, people have difficulty agreeing on the definition of consciousness. Past attempts to subdivide it into animal versus rational, normal versus abnormal, or other hierarchical subdivisions illustrate the obvious differences in proposed conscious states, and thus in defining consciousness itself.

The goal of this paper is not, therefore, to attempt to define consciousness, other than to say that, for the purposes of this discussion, we will consider consciousness to be that which we attribute to the mind. The objective instead will be to investigate the wide range of theories regarding the organ responsible for consciousness, and specific examples will be given with each cultural exploration. Although to most Western physicians the brain seems the logical choice, this has not always been the case and is still arguable across populations. Even the historical and crosscultural study detailed in this paper, although limited in its perspective, provides a glimpse of the importance of these questions to humanity in general and the difficulty with which they are answered. Broadly, the discussion has been divided into Eastern and Western texts.

\section{Eastern Thought}

Looking back into premodern theories of consciousness, we are confronted with some very different views on the nature of human beings and their composition. The Book of the Dead detailed the role of the heart from the 16th-century BC papyrus of Ani. ${ }^{5}$ Egyptian hieroglyphics illustrated the heart, which was pictured as removed from the body to be weighed on a scale with a feather on the other side. The feather represented ma'at; that is, truth or divine order. This demonstrates the Egyptian civilization's belief in the importance of the heart not only in judgment of the truth but also as a measure of self-worth in the afterlife. 
The Hindu and Chinese ancient literature, such as the Bhagavad Gita, subdivided consciousness into external and internal. ${ }^{19}$ The external consciousness is the universal consciousness that gives rise to the self: "atma" or soul. Indirect importance is given to the cardiopulmonary system for the purification of the soul through yoga and meditation. In the Rig Veda, texts such as "He who, possessed of food, hardens his heart against the feeble man craving nourishment, against the sufferer coming to him (for help), and pursues (his own enjoyment even) before him, that man finds no consoler," 19 illustrate the importance of the heart in making moral judgments.

To define the physical bases of consciousness in sacred text, it is difficult to underestimate the emphasis given to the heart as an organ of thought and decision-making. In the Old Testament, the heart was the locus of intellectual, moral, and psychological life. Hebrew words such as "Lev or leb," "lebab," "libba," "beten," "kereb," and "me(j)'im" refer and are translated to mean "organ heart." Looking at the context in which the word was used, one can infer the authors' understanding of its function. Examples are as follows: the heart is the seat of consciousness (Proverbs 14:10). It was with the heart that one feared (Jeremiah 32: 40), served God (1 Samuel 12:20), accepted divine teachings (Proverbs 7:3; Isaiah 51:7), trusted in God (Proverbs 3:5), meditated (Psalms 19:14), intended (Jeremiah 23: 20), willed (Exodus 14:5), imagined (Genesis 8:21), and pondered (Psalms 4:4). Furthermore, the heart was referred to as the seat of wisdom (1 Kings 3:12), of thought and reflection (Jeremiah 24:7; Luke 2:19), and of memory (Psalms 31:19; 1 Samuel 21:12), as well as being an instrument of belief (Romans 10:10) and the principle of action (Exodus 35:21). As in the Rig Veda, moral and intellectual ignorance and lack of an internal ability to "see" spiritual truths was indicated by referring to the heart as "hard," "strong," "firm," and "fat" (Psalms 119:70, Isaiah 6:10; Acts 28:27). ${ }^{18}$

This theme is carried over into the New Testament as well: "Blessed are the pure in heart, for they shall see God" (Matthew 5:8) or "honor me with their lips ... their heart is far from me" (Matthew 15:8). The heart is mentioned as the seat of intelligence (Matthew 12:34; Mark 7:21; 11:23; Acts 11:23), understanding (Matthew 13:19), pondering (Luke 2:19), decision-making (Acts 11:23), and thought (Luke 2:35). ${ }^{18}$

Much like their Semitic counterparts, Islam and the succeeding disciplines and sciences that developed to fruition following the death of the Prophet Muhammad conceive of physiology and anatomy, in general, as symbolic prolongations of humanity's psychology and pneumotology. In fact, the birth of Islam in the Arabian peninsula geographically positioned it to act like a crucible of the prevalent theories and practices found in neighboring continents. Additionally, Islam's historical position as the final major premodern civilization lends it special placement since the theories and practices acquired or transmitted had stood the test of time-an aggregate of nearly 2000 years of human knowledge. Just as it found itself as the final major classical civilization, from another perspective the Islamic civilization's momentum propelled medieval European civilization toward its own Renaissance. ${ }^{26}$ Thus, the Islamic sciences and disciplines are a hybrid of Hel- lenistic, Indian, Persian, and Chinese sciences, circumscribed by Islam's sacred text, the Koran, and the Prophetic traditions of Muhammad.

As noted earlier, ancient Chinese and Hindu sacred literature suggests an external and internal consciousness, or a universal and particular consciousness; hence, a hierarchy of consciousness in which the latter derives from the former. According to Arthur Lovejoy's study on the great chain of being, in which consciousness and being in premodern philosophy are interrelated concepts, this philosophical theory, which can be considered as the premodern civilization's presiding idea (inasmuch as we in the modern world consider that matter is the ultimate ground of all existence) is like the golden thread through all premodern civilizations. Islam participates in this presiding idea, especially as reflected in the Epistles of the Brethren of Purity (Ikhwan al-Safa). An enigmatic group whose identity is shrouded in speculation, the Brethren took an active interest in the symbolism of physiology and anatomy. They, among many significant Islamic philosopher/ scientists, place great importance on the Koranic idea that creation is a "sign" from God. In the case of anatomy and physiology, man reflects the universe as much as the universe reflects man. This micro-/macrocosmic idea undergirds much of the Islamic sciences and disciplines to the extent that the Brethren assign measurement and proportion to the human body, compare it to a city, and also associate illnesses of various body parts with planets. ${ }^{26}$ The point is that the symbolism of physiology and anatomy factored deeply into the Islamic interpretation of the natural world, and failure to mention this fact would be an incomplete or distorted representation of the sciences in Islam.

The use of the heart as a symbolic referent is similar in Islam's predecessors, Judaism and Christianity, and, farther east, Hinduism. All of these religions refer to the heart symbolically as the organ of moral judgment. Al-Ghazzali was probably the most famous commentator in Islam on disciplining the limbs of the human body to purify the heart of man, which for him was the locus of intention. His work Alchemy of Happiness proceeded into a gradual moral education, moving from the deeper levels of consciousness to the psychic forces within humanity to rules and regulations of its interactions with the world and with God. In an early passage on the heart, al-Ghazzali categorically stated:

Your true nature lies in that internal spirit. ... We call it the "heart". . . . Not to the lump of flesh which is found in the left side of the chest; it has no special merit and is possessed also by the beasts, the dead, and can be seen by the external eye. . . The true nature of the heart is not of this world. . . the external flesh is a vehicle, and all the limbs and organs of the body are its soldiers. ... [The heart] is the monarch of the entire body. ${ }^{1}$

In this quote al-Ghazzali appears to have distinguished between the physical heart and symbolic heart. Subsequent chapters relate to unveiling the true nature of the self of this symbolic heart, or, to stay constant with our terminology, the true nature of our consciousness. Indeed, the veils are removed by disciplining the limbs through engaging in the right moral conduct. 
The ultimate end of these unveilings is to perceive the immanence of God, or, from another perspective, the external/universal consciousness, from when the particular soul/consciousness derives. Although from the perspective of al-Ghazzali's writings their ideas are limited, modern analytic and continental philosophers such as Richard Rorty, Richard Bernstein, and Jurgen Habermas have argued that consciousness is not just a reflection of consensus reality but the source and spectrum of perceiving reality. This is not to prove al-Ghazzali's theory of perception, but to assert that consciousness is an active and creative force that shapes humanity's experience of the environment and relationship to it. This modern philosophical conclusion implies-perhaps obliquely-that different levels of conscious states create different perceptions. For alGhazzali, this would mean that through moral disciplining true consciousness is achieved; thus perceiving the universal consciousness that sustains all other lower levels of consciousness, including the internal one. Domination of true consciousness by lower sensorial appetites renders the heart sick, clouding it so that it is unable to recognize and experience the true, universal consciousness. Like his religious predecessors, al-Ghazzali held that an unhealthy consciousness can misguide moral judgments and cause one to fall into vice, a "hardening of the heart;" to address such moral turpitude he dedicated several dense chapters on how to recover a healthy consciousness. ${ }^{1}$

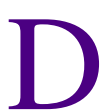
ISCUSSION OF THE BRAIN in al-Ghazzali's Alchemy of Happiness appears to be scant, given that he was a specialist on the symbolic heart and not on the physical heart per se. However, he indicated in a chapter titled "Meditations on the Wonders of God" that from the brain "nerve channels [that is, the spinal cord] come out and reach the entire body, so that the faculties of sense and movement flow throughout it."' Thus, al-Ghazzali suggests that the brain is the "control office" in sensing the world and that the physical heart, as controlled by the symbolic heart, vitalizes the brain to perceive and interact with the world in a particular way, whether virtuously and nobly or in a disgraceful and confused manner. ${ }^{1}$

A more thorough analysis of the heart/brain and consciousness is provided by other Islamic thinkers such as Ibn Sina and Ibn Rushd, whom we will discuss later. Returning to the Koran for a moment, the word most often to denote heart ("qalb") is rooted in the word for fluctuation. Other Arabic terms also denote the heart; however, they relate more to its subtle psychospiritual dimensions. Despite this lexical variety, the organ devoted to morality, thought, and intention is the heart. "Allah will not call you to account for thoughtlessness in your oaths, but for the intention in your heart" (2:225). As in the Old Testament, immorality in the Koran leads to the "hardening" of the heart $(5: 13)$. Ignorance and understanding is attributed to the heart, but "We have thrown veils on their hearts, so they understand it not" $(6: 25){ }^{10}$

Ibn Sina, a scholar of the Middle Ages, was influenced by Galen and Aristotle and yet supplanted them in influence in the history of medicine. He wrote extensively about his understanding of consciousness, and subdivided it into theoretical and practical. The practical moves the body into particular action through deliberations of prior expe- rience. Following the overall Aristotelian model of a human being's constitution, Ibn Sina believed that he or she is part mineral, vegetative, animal, and spiritual. As for the animal portion, the practical consciousness is related to appetite, imagination, planning, and affections. The theoretical dimension of consciousness is an imprint of the "universal form" or laws and principles, which are abstracted from the practical consciousness. In the final analysis, the consciousness is indivisible and immaterial because it is the simple and basic building block of all other concepts abstracted from the physical experience of the world. Ibn Sina found that consciousness is in every faculty and must be attached to any organ with life. ${ }^{16} \mathrm{In}$ the opening words by Ibn Sina on his chapter on Breath as related to consciousness and the heart, he stated:

The heart [is] made ... hollow in order that it should serve both as a storehouse of the breath and as the seat of manufacture of the breath. [T] he breath enable[s] the drives of the "soul" to be conveyed into the corresponding [organs]. In the first place the breath was to be the rallying-point for the faculties of the soul and in the second place it was to be an emanation into the various members and tissues of the body (whereby these could manifest the functions of those drives). ${ }^{4}$

Hence, the various organs are ensouled by breath, with the heart acting as the locus for breathing. Given that the heart precedes other organ development, Ibn Sina transferred this reasoning to breath too, asserting that one single breath accounts as the origin for others. Breath passes through the heart to fellow vital organs to enable them their "respective temperamental properties." For our purposes, the cerebrum receives breath from the heart, enabling sensation and movement through the "soft spongy sub-lingual glands." Thus, as Ibn Sina concluded in his introductory remarks on breath, within the brain lies the gustatory powers. Elsewhere he noted that nerves arise from the brain directly (or indirectly through the spinal cord) and are responsible thereby for movements of the head, face, and internal organs, whereas the spinal nerves supply the remaining organs. Thus, returning to Ibn Sina's notion of practical consciousness, sensations perceived are linked to the brain, thus evolving and maturing man's practical consciousness. ${ }^{4}$

Another Muslim philosopher of the Middle Ages was Ibn Rushd. The most important commentator on Aristotle of his time, he commented on perception (or, from Ibn Sina's perspective, the intersection of the theoretical consciousness and practical consciousness). The essence of Ibn Rushd's argument is derived from the logical inferences he drew from Aristotle's De Anima. The quagmire he attempted to resolve in his chapter on perception is how are the senses of perception not perceived by consciousness itself? Ibn Rushd noted that preceding philosopher/ scientists have debated this issue, some arguing that perceptions are affected by like perceptions and others arguing that perceptions are affected by unlike perceptions. By taking recourse to the classical Aristotelian notions of potentiality and actuality, he asserts that perceptions do not exist in actuality but only in potentiality:

Were [perception] to perceive itself then something would emerge by itself from potentiality to actuality without an external factor, and this does not occur. Just as that which is poten- 
tially combustible does not burn by itself without an external agent of combustion present, so with potential perception. If sensation could perceive its own subject, then it would be possible, for example, for wood to burn by itself without the presence of an external fire. ${ }^{3}$

With this philosophical move, Ibn Rushd continued his gloss on Aristotle in concluding that perceptions are affected by both like and unlike perceptions. In other words, the shift in perceptions from potentiality to actuality is rooted in the movement by what is unlike it, "namely the mover"- which is separate from the potentially perceiving subject—but acquires the movement by that which is like it.

However, avoiding Ibn Rushd's detailed account of the process of sensations, it appears that all tactile perception of the external senses is predicated on something he labels as "natural heat." Whether it is potential perceptions or actual perceptions, whether primary tangibles (composed of the four elements) or secondary tangibles (such as hardness or softness or the like), all perceiving creatures retain the medium of flesh. Prior to Ibn Rushd, Themistius held that flesh is the medium of touch and Galen held that nerves are the medium of touch, but Ibn Rushd asserted that "natural heat" is the substratum of touch, given that the other two opinions are not philosophically basic and simple and that both flesh and nerves are found throughout the entire body. Natural heat is the principle of all life that exists in the heart and arteries. The brain moderates the natural heat and the nerves that branch out from the brain share the brain's function of moderating natural heat. In other words, natural heat, as moderated through the brain and to a lesser extent the nerves, enables sensations to be perceived. ${ }^{11}$

Thus, summing Ibn Rushd's position on perception, the faculty of perception cannot be reliant on itself, given that that would be illogical; hence, the necessary division of potential and actual perception. Furthermore, the essence of that actual or potential perception, with the brain acting as the main juncture for perception, is the natural heat, whose seat is the heart. Both Ibn Sina and Ibn Rushd lend primacy to the heart, although Ibn Sina referred to it as breath and Ibn Rushd as natural heat, and both provide an essential role to the brain. The former conceives of it for gustatory ends and the latter as the moderator for the natural heat into the faculties of perception. Either way, it appears that some of the giants in Islamic thought consider the heart as the seat of consciousness and the brain as the controlling mechanism for consciousness, and ultimately perception. ${ }^{20}$ An apt metaphor for both philosophies is perhaps that consciousness is like the sea that keeps one afloat and perceptive, whereas the brain is like the boat's rudder guiding it over the sea, casting perceptions as intelligible so we can appropriately interact with the world around us.

\section{Western Thought}

A similar conceptual framework envelops the Western perspective regarding consciousness. This framework arises from two basic schools of thought, which still exist today. The first is that consciousness resides outside of the physical being (external soul) but is able to animate the body through specific organic pathways. The second is that consciousness arises from a certain organ within the body to exercise its will on the environment.

Over the centuries, the development of a concept of consciousness through the study of anatomy has been centered around the notion of an external soul. The remainder of this discussion will focus on Western scholars who defined the understanding of the mind-body connection of their region and their time. Although disagreements are apparent regarding the specific organ responsible, all seem to agree that life does not arise from living beings, but animates the inanimate.

First, it must be made clear that this is more a study of functional anatomy than of philosophy. Most thinkers in Western civilization who have attempted to understand consciousness have been scientists and physicians. Although they drew much of their knowledge from ancient philosophical texts, in them the roles of philosopher and scientist were intertwined. Before experimentation became the norm, observation and inference composed the scientific method. Influential ancient Western scientific texts therefore were difficult to differentiate from philosophy. The argument then becomes that when Greek "philosophers" spoke of the heart, they used the term metaphorically and were not referring to the actual cardiac muscle. On the contrary, the authors of the texts discussed in this section had developed a rather sophisticated understanding of human anatomy. Some discussions specifically refer to discovering the organic counterpart to the soul or mind. Others undertake a detailed analysis of the central nervous, cardiopulmonary, and digestive systems. Ultimately, the marriage of logic, observation, and eventual experimentation culminates in a fascinating maturation of centuries of accumulated knowledge. In the end, however, despite massive leaps toward understanding the workings of the liver, the purpose of the brain, and the function of the heart, we have not yet solved the complexities of consciousness. Even its true definition eludes us.

THE FOLLOWING DISCUSSION will demonstrate the evolution of a crude understanding of the human body into a refined study of functional anatomy. Specifically, the writings of Empedocles, Hippocrates, Aristotle, Galen, and Descartes will be reviewed. Interrelated themes and influences will be demonstrated.

A significant portion of the foundation for subsequent study regarding these matters is rooted in the work of Empedocles (495-435 BC). Empedocles defined the concept of a simplified universe consisting of four elements, ${ }^{17}$ each of which are the basic units of all matter, including the human body. He associated these four elementsearth, air, fire, and water-with four humors: mucus, blood, yellow bile, and black bile. Furthermore, he associated specific organs with each humor: brain, heart, liver, and spleen, respectively. Finally, certain states of mind were assigned to each organ, given its associated humor. To the brain went sluggishness, to the heart, cheerfulness, to the liver, irritability, and to the spleen melancholy. It is the imbalance of these humors, he argued, that causes disease. . $^{17,25}$

Equally essential in developing an understanding of the mind-body connection was the concept of "pneuma." 
Pneuma was defined in ancient Greek both as "breath" and "life." Widely accepted for centuries was the notion that life was inspired, distilled within the body, and responsible thereafter for particular aspects of living. The distillation process, however, remained a source of great debate, as discussed later.

Although Empedocles had not addressed consciousness directly, his teachings greatly influenced a contemporary physician. Hippocrates (ca. $400 \mathrm{BC}$ ) further developed the theories of humoral imbalance and discussed in detail resulting pathological conditions and possible cures. More important, however, he first began to argue against the idea of cardiopulmonary consciousness. In his work $\mathrm{On} \mathrm{An}$ cient Medicine, he made clear that the prevailing thought regarding the things we today assign to the "mind" were assigned organically to the heart and diaphragm. He then made the argument, based on observation of wounds encountered at war, that it is the brain, not the heart, that houses the conscious mind: ${ }^{15}$ "Wherefore the heart and the diaphragm are particularly sensitive, they have nothing to do, however, with the operations of the understanding, but of all these the brain is the cause."

He then went on to delineate the functions he believed to originate in the brain, including emotion, wisdom, knowledge, senses, justice, understanding good and bad, reason, delirium, and dreams. Clearly Hippocrates in this excerpt was in the midst of a historic anatomical discussion that begins to drive the focus of organic consciousness from the cardiopulmonary to the central nervous system. Interestingly, however, he did so by arguing that the pneuma, although brought into the body through the diaphragm, must be stored within and distributed from the brain..$^{23}$

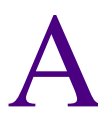
CENTURY LATER, Aristotle (384-322 BC) built on the theories of Hippocrates. Whereas Hippocrates began to define the route of pneuma through the brain, Aristotle developed further the distillation process. His theory, referred to as the tripartite soul, deconstructs life based on observations of the environment. ${ }^{2}$ Specifically, he began to separate life from consciousness, arguing that although consciousness requires pneuma, the converse is not also true. The differences among plant, animal, and human life were clear to Aristotle, and he attempted to make sense of this disparity, given that the same pneuma was responsible for bringing all three to life. There must, therefore, have been three "spirits" within pneuma, which were distilled differently within different forms of life. The tripartite theory suggests the existence of vegetative, animal, and rational spirits. Plant life, although exposed to the entire pneuma, was only capable of using the vegetative spirit, responsible for growth and acquisition of sustenance. Animal life, being slightly more sophisticated, uses both vegetative and animal spirits not only for growth, but to move and sense as well. Building on basic life, animals begin to perform the basic motor and sensory functions we assign to the brain today. Finally, rational spirits-found only in human beings, according to Aristotle - are responsible for self-awareness, higher-level cognition, and other aspects of the conscious mind. All three spirits can only be distilled and made useable within the human body.

Hippocrates and Aristotle leapt conceptually to a new understanding of consciousness, basing their conclusions both on observation and prior teaching. In the same way Galen (ca. AD 129-200) expanded the study of functional anatomy, but brought experimentation and demonstration to the forefront..$^{12}$ Unlike those before him who relied heavily on observation and inference, Galen began to meticulously deconstruct animals and humans to their most fundamental anatomical parts. ${ }^{12,13}$ His dissections and demonstrations were unsurpassed at the time and were the basis for his legendary clinical practice. Within his discoveries regarding the function of organs he developed a rudimentary understanding of the circulation of the blood and the communication among the brain, spine, and peripheral nerves ${ }^{21,22,23} \mathrm{He}$ then added this new understanding to the foundation of his ancestors when he assigned specific organs to the tripartite soul described by Aristotle. Specifically, he surmised that the liver to had to do with nutrition and digestion, and therefore may house the vegetative spirit. It is the heart and diaphragm, on the other hand, that distill the animal spirit and are affected by it. This is in line with Hippocrates' view that the body is affected by the workings of the brain. With respect to the cardiopulmonary system, Galen described a sympathetic response to emotion. Finally, he assigned the brain the role of storing the animal spirits to be distributed for purposes of movement and sensation as needed. More important, he believed the rational spirit was housed within the brain as well. ${ }^{23,24}$ So whereas Aristotle provided a theoretical definition of consciousness, it was Galen who created the anatomical view.

Again, his view was contrary to the widely accepted pulmonary theory of consciousness that had survived 600 years after Hippocrates first argued against it. Like Hippocrates, Galen had supported his theory through observation initially. His environment was a gladiator school, where he noted that the deficit caused by brain injury was proportional to the proximity to the ventricular system. ${ }^{21,23}$ Deeper lesions were more serious. In fact, he further observed that lesions to the lateral ventricles impaired modalities associated with animal spirits such as sensation and movement, whereas lesions near the third ventricle affected reason and judgment. He considered these third ventricular lesions to be the most disturbing, affecting that which made humans human. On the basis of these observations, Galen took his brain-centric theory one step further, suggesting that the animal spirit was stored in the lateral ventricles and the rational spirit in the third ventricle.

Undoubtedly, criticism arose from physicians who still argued that the rational spirit, the mind, was housed within the heart, and that all animation arose from there. In a famous demonstration, Galen cut the laryngeal nerve of a squealing pig. ${ }^{14} \mathrm{He}$ then astounded his audience by confirming not only the role of this fiber in controlling movement and voice, but also the connection of this nerve to the brain rather than the cardiopulmonary organs. This type of experimentation ultimately set Galen apart and advanced his theories in ways that Hippocrates could not. Galen's medical texts became standard in Western civilization and provided the foundation for further exploration centuries later.

In the 17th century, Descartes picked up where Galen left off. Like Aristotle, however, he was more interested in conclusions regarding the definition of consciousness based on 
logic and observation. He was more philosopher than anatomist, but despite this limitation he proposed the pineal gland as the most likely organic counterpart to the soul. In his letters after writing the Treatise of Man he stated,

My view is that this gland is the principal seat of the soul, and the place in which all our thoughts are formed. The reason I believe this is that I cannot find any part of the brain, except this, which is not double. Since we see only one thing with two eyes, and hear only one voice with two ears, and in short have never more than one thought at a time, it must necessarily be the case that the impressions which enter by the two eyes or by the two ears, and so on, unite with each other in some part of the body before being considered by the soul. Now it is impossible to find any such place in the whole head except this gland. ${ }^{8}$

Later in The Passions of the Soul he wrote, "the soul is really joined to the whole body, and that we cannot properly say that it exists in any one part of the body to the exclusion of the others." 7 Then he went on to say, "nevertheless there is a certain part of the body where it exercises its functions more particularly than in all the others." ${ }^{\circ, 7}$ Descartes posited that the part of the body in which the soul directly exercises its functions is not the heart at all, or the whole of the brain. It is rather the innermost part of the brain, which is a certain very small gland situated in the middle of the brain's substance and suspended above the passage through which the spirits in the brain's anterior cavities communicate with those in its posterior cavities.

Like his predecessors, Descartess used his knowledge of anatomy coupled with philosophical instruments to attempt to answer a question that we humans have innately asked. Are we greater than the sum of our parts? If so, which part is the closest to that which lies beyond our understanding? Which organ or tissue is responsible for the mind? Although many of us assume that the brain is the seat of consciousness, various scholars in the modern era continue to search for the mind-body connection. Some use functional magnetic resonance imaging and others meditation. Even in the 21st century, there is no clear consensus between or within communities, scientific or otherwise, on the brain's capacity for making us who we are. Perhaps, by its nature, our consciousness - our awareness of our surroundings and ourselves-is a function of what surrounds us, and must therefore change as the world changes and as we change.

\section{References}

1. Al-Ghazzali A: Alchemy of Happiness. Crook JR, trans. Chicago: Great Books of the Islamic World, 2005, pp 13-14, pp 958

2. Aristotle: De Anima (On the Soul). Lawson-Tancred H, trans. New York: Penguin Classics, 1986

3. Averroës: Middle Commentary on Aristotle's De Anima. A Critical Edition of the Arabic Text with English Translation, Notes, and Introduction. Ivry AL, trans. Provo, UT: Brigham Young University, 2002, pp 60-61
4. Avicenna: The Canon of Medicine. Gruner OG, Shah MH, trans. Chicago: Great Books of the Islamic World, 1999, pp 108-145

5. Budge EAW (trans): The Book of Dead: (The Papyrus of Ani) Egyptian Text Transliteration and Translation. Mincola, NY: Dover Publications, 1967

6. Descartes R: The Passions of the Soul. Voss SH, trans. Indianapolis: Hackett Publishing Company, 1989

7. Descartes R: The passions of the soul in Selected Philosophical Writings. Cottingham J, Stoothoff R, Murdoch D, (trans). Cambridge, England: Cambridge University Press, 1999, pp 218-238

8. Descartes R: The Philosophical Writings Of Descartes. Cottingham J, Stoothoff R, Murdoch D, trans. Cambridge, UK: Cambridge University Press, 1999

9. Empedocles: Empedocles: The Extant Fragments. Wright MR, (ed): London: Bristol Classical Press, 1995

10. Erfani MI: A-Z Ready Reference of the Quran. Based on the Translation by Abdullah Yusuf Ali. Delhi: Goodword Books, 2004, pp 394-399

11. Fakhry M: Averroes, Ibn Rushd. His Life, Works and Influence. Oxford: Oneworld Publications, 2001, pp 58-60

12. Galen: On the Natural Faculties. Brock AJ, trans. Whitefish, MT: Kessinger Publishing, 2004

13. Galen: On the Usefulness of Parts of the Body. May MT, trans. Ithaca, NY: Cornell University Press, 1968

14. Gross CG: Galen and the squealing pig. The Neuroscientist 4: 216-221, 1998

15. Hippocrates: On Ancient Medicine. Whitefish, MT: Kessinger Publishing, 2004

16. Khalidi MA (ed): Medieval Islamic Philosophical Writings. Cambridge, UK: Cambridge University Press, 2005, pp 27-58

17. Kingsley P: Ancient Philosophy, Mystery, and Magic: Empedocles and Pythagorean Tradition. New York: Oxford University Press, 1997

18. Lind RE: The Seat of Consciousness in Ancient Literature. Jefferson, NC: McFarland \& Co. Inc, 2007, pp 72-79

19. Mascaró J (trans): The Bhagavad Gita. London: Penguin Classics, 1962, p 328

20. Nasr SH: An Introduction to Islamic Cosmological Doctrines. Albany, NY: State University of New York, 1993, pp 96-104

21. Scarborough J: Galen and the gladiators. Episteme 5:98-111, 1971

22. Scarborough J: Galen Redivivus: an essay review. J Hist Med Allied Sci 43:313-321, 1988

23. Siegel RE: Galen on Psychology, Psychopathology, and Function and Diseases of the Nervous System. An Analysis of his Doctrines, Observations and Experiments. New York: Karger, 1973

24. Smith A: The Mind. New York: Viking Press, 1984

25. Smith WD: The Hippocratic Tradition. Ithaca, NY: Cornell University Press, 1979

26. Wallace-Murphy T: What Islam Did For Us: Understanding Islam's Contributions to Western Civilization. New York: Watkins Publishing, 2006

Manuscript submitted May 11, 2007.

Accepted June 20, 2007.

Address reprint requests to: Chris Karas, M.D., 4614 Meekison Drive, Columbus, Ohio 43220. email: ckaras@yahoo.com. 